\title{
IMPROVEMENT THE CAVITATION EROSION RESISTANCE OF AI-Mg ALLOYS BY TIG SURFACE REMELTING
}

\author{
Florin FRANT, Ion MITELEA, Ilare BORDEASU, Ion-Dragos UTU, \\ Corneliu Marius CRĂCIUNESCU \\ Politehnica University of Timisoara, Timisoara, Romania, EU, \\ florin.frant@student.upt.ro,ion.mitelea@upt.ro,ilare.bordeasu@upt.ro,dragos.utu@upt.ro. \\ corneliu.craciunescu@upt.ro
}

https://doi.org/10.37904/metal.2021.4238

\begin{abstract}
Aluminum-based alloys (Al-Mg, Al-Si-Mg, Al-Zn-Mg, etc.) are intended for the manufacturing of parts subjected to intense stresses by cavitation erosion. This complex phenomenon includes both the hydrodynamic factors of the liquid and the microstructure, hardness and ductility characteristics of the material. The present paper describes a method of increasing cavitation erosion resistance by using the local TIG remelting technique of the AIMg3 alloys surface. The experimental tests were performed according to ASTM G32-2016 standard. The response of the material to each value of the heat input was investigated by measuring the mass loss as a function of the cavitation time and by analysing the damaged surfaces using the optical and scanning electron microscopy. It has been shown that the TIG surface modification treatment increases the resistance to cavitation erosion of the alloy, as a consequence of the higher chemical and microstructural homogeneity and finishing of the granulation.
\end{abstract}

Keywords: Cavitation erosion, TIG melting, microstructure

\section{INTRODUCTION}

Surface degradation of engineering components by cavitation erosion is due to the appearance, development and collapse of bubbles in liquids, as a result of pressure fluctuations, from values below the vaporization to values lots above that are inside the bubble. By the collapse of the bubbles, near the surface of the material, shock waves are generated whose pressure can reach 1-1.5 GPa and micro-jets whose speed reaches approx. $130 \mathrm{~m} / \mathrm{s}$ [1-4]. They repeatedly hit the surface of the piece leading to plastic deformations, microcracks and pinches, respectively cavities, by removing the material from the impacted area. Generally surface properties have a significant influence on the performance of components exposed by cavitation erosion. To improve the cavitation erosion behaviour of metals and metal alloys and to extend the lifetime of the components made from them, a series of surface engineering techniques are used to modify surface properties, such as thermal spraying, local remelting, thermochemical nitriding treatments, hard layer deposited by welding, etc. [3,4].

Al alloys are frequently used in the manufacture of components that operate under cavitation erosion conditions, such as cylinder liners, pistons, pumps, valves and combustion chambers. They usually have poor performance in cavitation erosion.

This paper analyses a method of improving the cavitation erosion resistance by local surface remelting using the TIG electric arc. 


\section{MATERIAL, EXPERIMENTAL PROCEDURE}

The investigated Al-Mg alloy, type EN AW - 5754 A (3.3535 Aluminum), which was delivered in the form of sheet with a thickness of $20 \mathrm{~mm}$ has the following chemical composition (in wt\%): $95.29 \mathrm{Al} ; 3.15 \mathrm{Mg}$; $0.32 \mathrm{Si}$; $0.29 \mathrm{Fe} ; 0.42 \mathrm{Mn} ; 0.24 \mathrm{Cr} ; 0.08 \mathrm{Cu} ; 0.12 \mathrm{Zn} ; 0.09 \mathrm{Ti}$.

The local surface remelting was performed with the help of a device to which the TIG welding installation was attached (Figure 1).

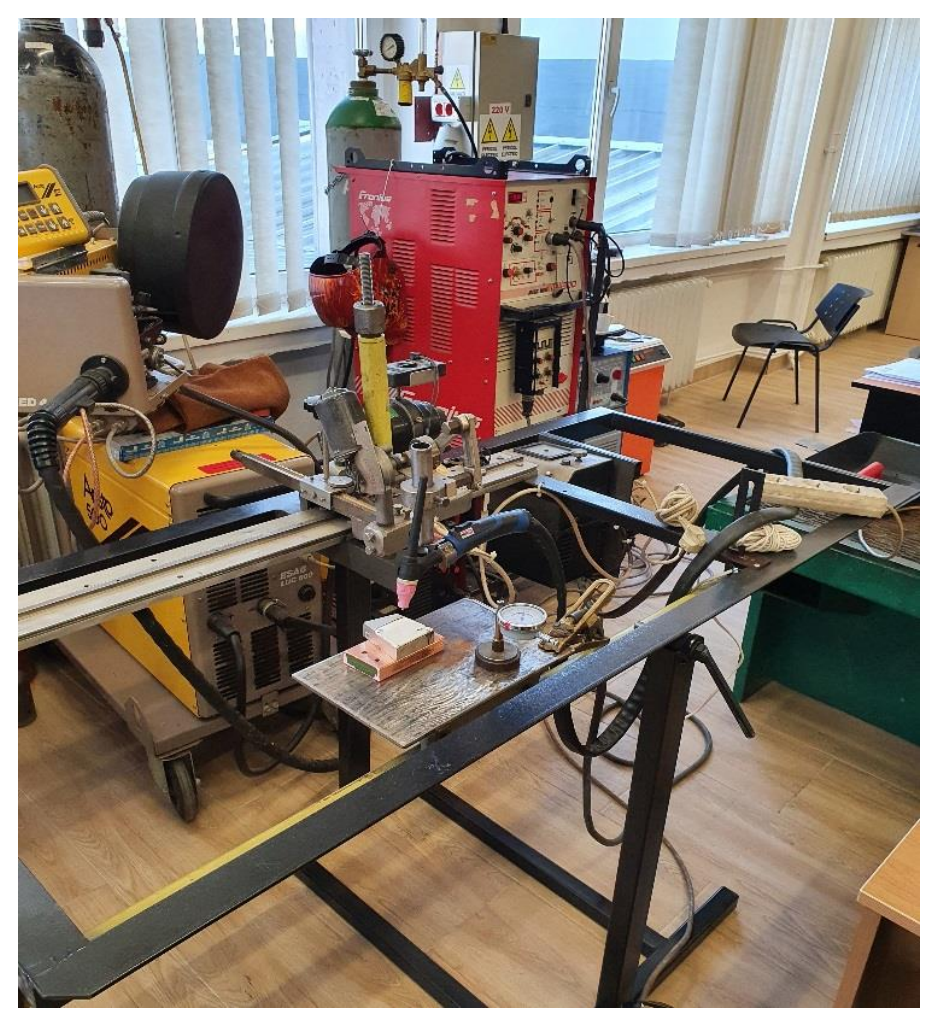

Figure 1 The experimental stand used

The remelting parameters used are given in Table 1.

Table 1 TIG regime parameters

\begin{tabular}{|c|c|c|c|c|}
\hline $\begin{array}{c}\text { Number } \\
\text { of layers }\end{array}$ & $\begin{array}{c}\text { Current } \\
\boldsymbol{I}_{\boldsymbol{s}}(\mathrm{A})\end{array}$ & $\begin{array}{c}\text { Voltage } \\
\boldsymbol{U}_{\boldsymbol{a}}(\mathrm{V})\end{array}$ & $\begin{array}{c}\text { Welding speed } \\
\boldsymbol{V}_{\boldsymbol{s}}(\mathrm{cm} / \mathrm{min})\end{array}$ & $\begin{array}{c}\text { Linear energy } \\
\boldsymbol{E}_{\boldsymbol{l}}=\boldsymbol{I}_{\boldsymbol{s}} \cdot \boldsymbol{U}_{\boldsymbol{a}} /\left(\boldsymbol{V}_{\boldsymbol{s}} \cdot \mathbf{6 0}\right)(\mathrm{J} / \mathrm{cm})\end{array}$ \\
\hline 1 & 110 & 10.4 & 10 & 6864 \\
\hline 2 & 150 & 12 & 10 & 10800 \\
\hline 3 & 190 & 13.6 & 10 & 15504 \\
\hline
\end{tabular}

Other process data:

- $\quad$ tungsten electrode diameter: $2.4 \mathrm{~mm}$;

- $\quad$ electrode distance - piece: $2 \mathrm{~mm}$;

- $\quad$ the step between two successive passes: $3 \mathrm{~mm}$;

- $\quad$ temperature between passes: $25^{\circ} \mathrm{C}$;

- $\quad$ argon flow rate used as shielding gas: $8 \mathrm{l} / \mathrm{min}$.

Subsequently, surface remelted samples for cavitation tests and microstructural studies were taken. 
Cavitation tests were performed in accordance with the international standard G32-2016 (the stationary specimen method) [5]. The test equipment contains a high frequency generator of $500 \mathrm{~W}$, a transducer with piezoceramic crystals, an amplifier for mechanical vibrations and a water vessel with cooling oil, in which the test specimen is inserted (Figure 2). The vibration frequency was $20 \pm 0.2 \mathrm{kHz}$, and the vibrations amplitude was $50 \mu \mathrm{m}$. The distance between the sample and the tip of the sonotrode was $1 \mathrm{~mm}$. The test medium was distilled water maintained at $22 \pm 1^{\circ} \mathrm{C}$.

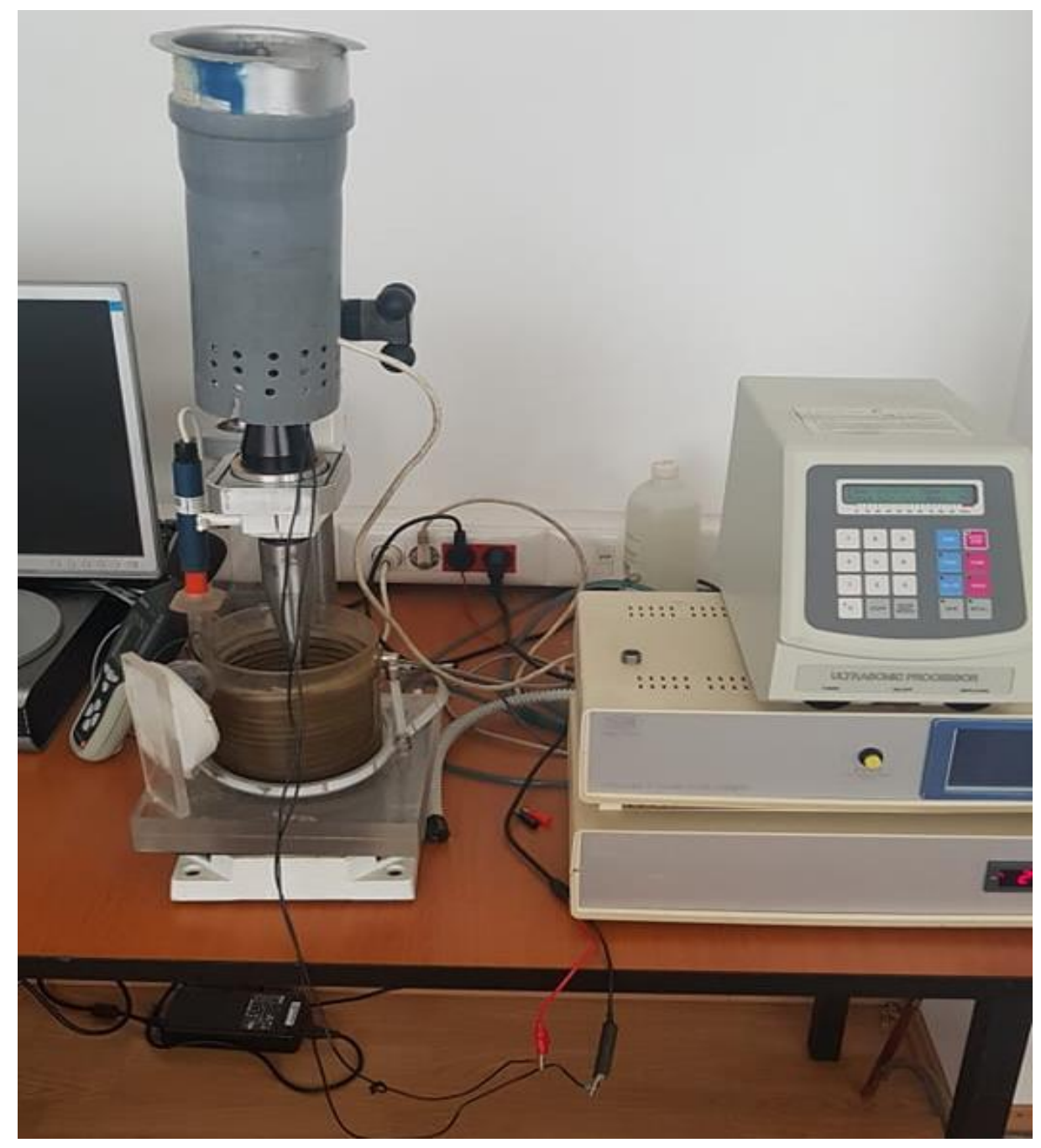

Figure 2 Image of the experimental cavitation test stand

For each structural state of the material, 3 samples were cavitated which testing surface was rectified and polished to remove any mechanically hardened layer that may form during their preparation. The total duration of each test was 165 minutes and was divided into 12 intermediate periods (one of 5 and 10 minutes and 10 of 15 minutes each).

At the beginning and at the end of each testing period, the samples were washed under tap water, distilled water, alcohol, acetone, dried under hot air and weighed.

Before beginning and ending of each intermediate test period, the surfaces exposed to cavitation were examined with the naked eye and photographed with the high resolution Canon Power Shot A480 in order to reveal the degradation of the surface exposed to the cavitation attack. Weighing was done with an analytical balance whose accuracy is 5 decimals (up to 0.00001 grams).

At the end of each intermediate test period " $i "$, the corresponding weight loss $\Delta m_{i}$, was determined. 
The cumulative eroded mass was calculated by the relation (1):

$m_{i}=\sum_{i=1}^{12} \Delta m_{i}$

Based on the mass losses, the values of the erosion rates, corresponding to each intermediate period, were determined.

The analysis of the morphology of the damaged surfaces, after the completion of the cavitation tests, was performed by scanning electron microscopy.

\section{RESULTS AND DISCUSSIONS}

\subsection{Cavitation curves}

Figures 3 and 4 show the characteristic curves of cavitation erosion, which indicate the variation of the accumulated mass losses and the related erosion rates, with the attack time. The obtained data show that using remelting current values of $150 \mathrm{~A}$, the mass losses, achieved after 165 minutes of cavitation attack are only $11.42 \mathrm{mg}$, and the erosion rate decreases to values of $0.08 \mathrm{mg} / \mathrm{min}$.

The explanation is based on the structural changes generated by the remelting process using TIG electric arc which is materialized by finishing the granulation and microstructure of the surface layer accompanied by an increase in hardness to values of $60 \ldots 72 H V_{0.3}$. It is known that the finer the granulation, the larger the surface boundary between the grains, the higher the deformation resistance and the lower the cavitation erosion rate.

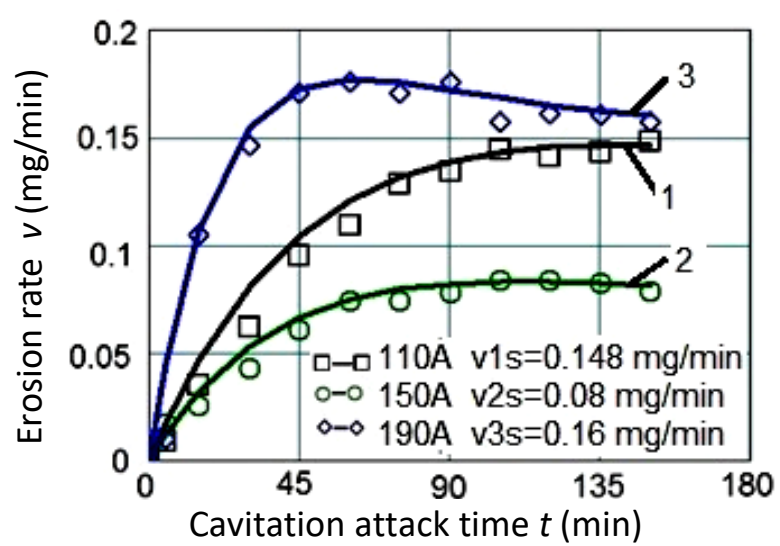

Figure 3 Comparisons of eroded masses depending on the attack time, specific

to the three treatment regimes

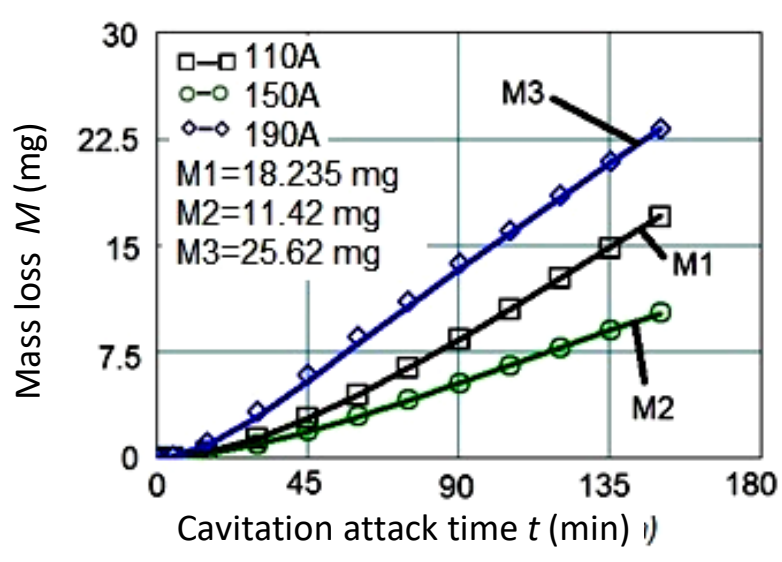

Figure 4 Comparisons of erosion rates depending on the attack time, specific to the three treatment regimes

\subsection{Topography of surfaces eroded by cavitation}

Figure 5 highlights the macroscopic image of the sample surface after TIG remelting at three current values and subsequently subjected to cavitation attack at variable time durations. It is noted that until the minute 30 the first two regimes of remelting maintain practically unchanged the aspect of the surface, and at longer durations appear and intensify both the number of pitting and their dimensions. For remelting currents of 150 $\mathrm{A}$, the surface damage is the smallest, and for currents of $190 \mathrm{~A}$ it is the most severe. These results are fully agreed with those of the cavitation curves from Figures 3 and 4 .

Scanning electron microscopy analysis, after finishing the cavitation test (165 minutes), of the remelted samples surface at a current of $150 \mathrm{~A}$. Figure 6 demonstrates that this alloy suffers a degradation similar to metals with crystalline face-centred cubic lattice, meaning ductile fracture on the entire surface. Material losses 
occur in isolated regions with the formation of striated craters (cavities) with a flat bottom probably Figures 6 a,b. Metallographic investigations have shown that after the local surface remelting, the initial microstructure consisted of the a solid solution with $\mathrm{Al}$ base and the secondary phase $\mathrm{Al}_{3} \mathrm{Mg}_{2}$ undergoes an pronounced granulation finishing due to the increase of the melting subcooling $[6,7]$.

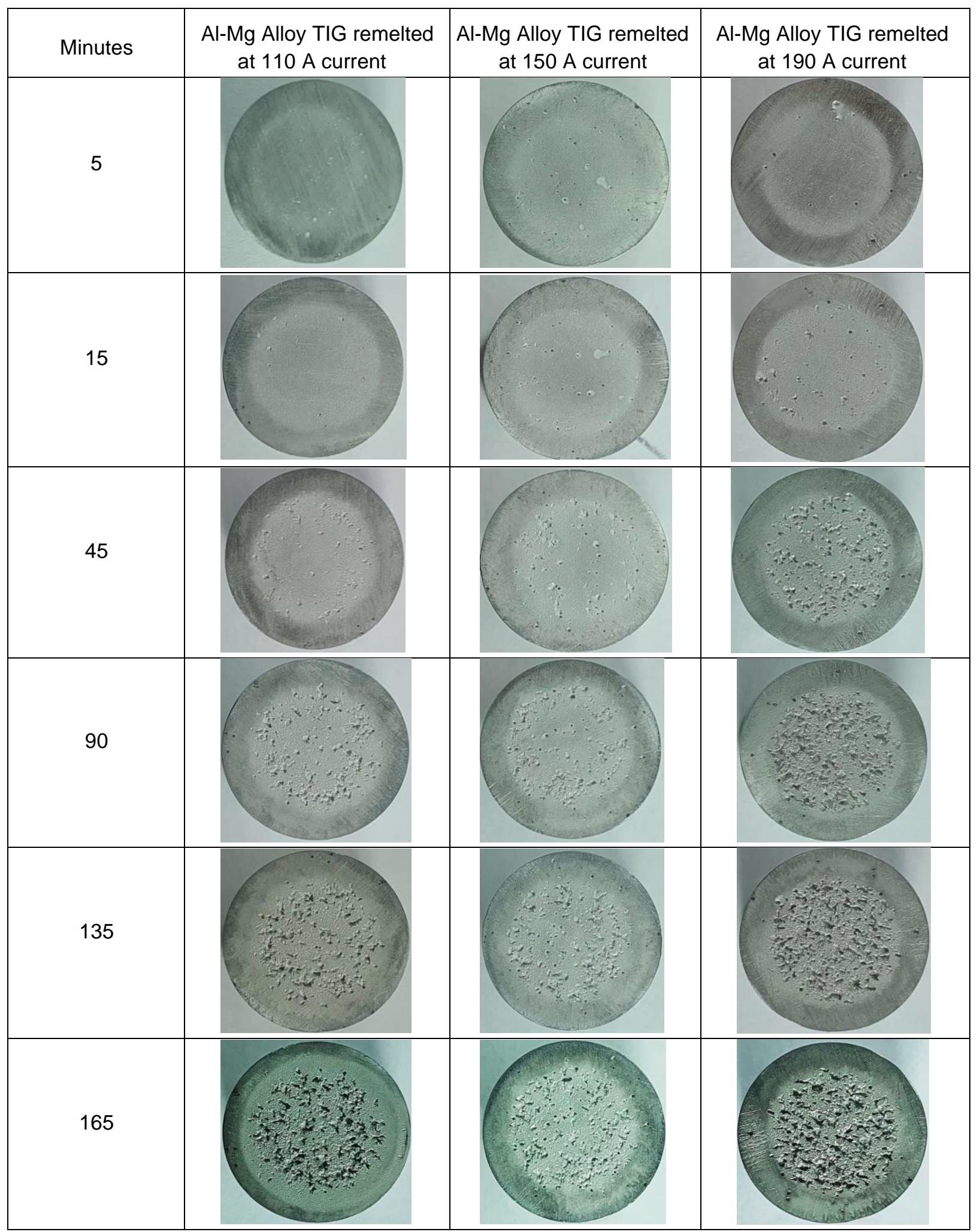

Figure 5 Macroscopic appearance of the surface of the samples used at various cavity attack times 


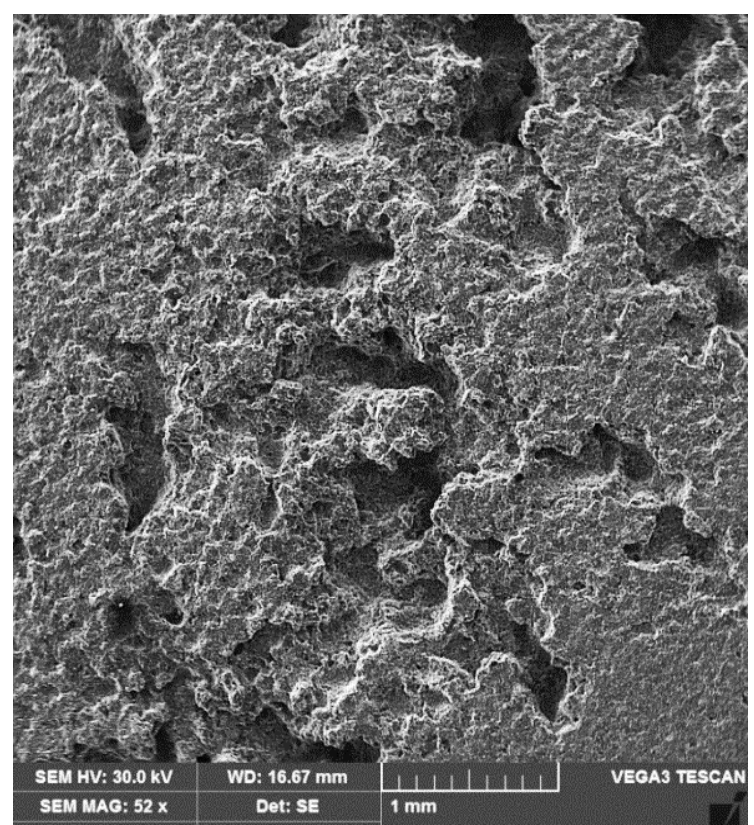

$-a-$

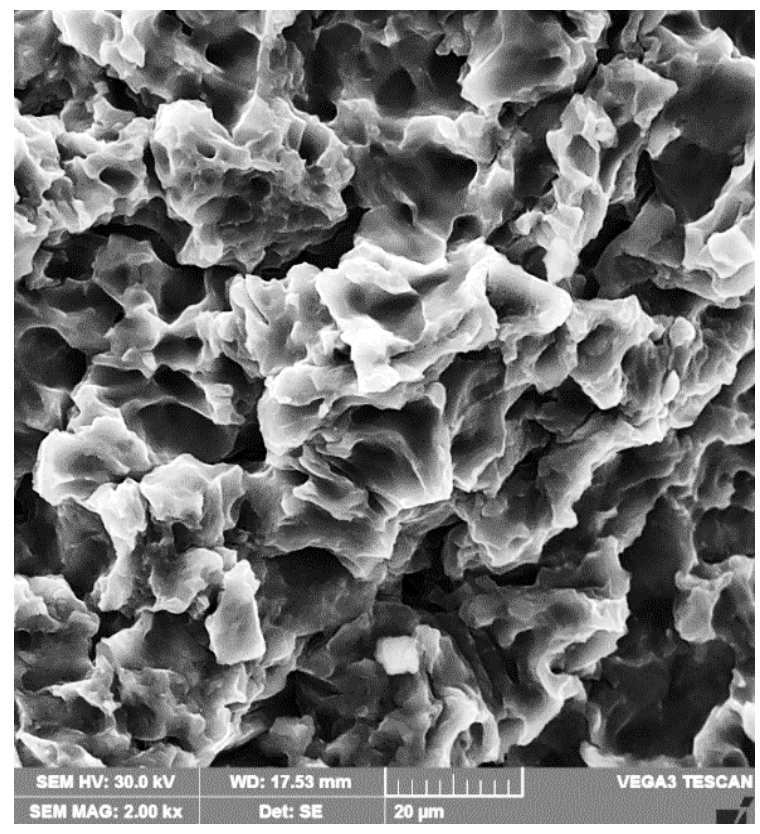

- b-

Figure 6 SEM image of the WIG melted surface at $150 \mathrm{~A}$ and tested in cavitation for $165 \mathrm{~min}$

\section{CONCLUSIONS}

TIG arc remelting at a current of $150 \mathrm{~A}$, of the AIMg3 alloys surface (EN AW - $5754 \mathrm{~A}$ ), after 165 minutes of cavitation attack, favours a decrease of the mass losses by about $60 \%$ compared to the usage of a remelting current of $110 \mathrm{~A}$ and by about $124 \%$ using a current of $190 \mathrm{~A}$.

From the point of view of the rate erosion value towards which the curve $v(t)$ tends, Figure 4, at 165 minutes, the decrease achieved by using a remelting current of $150 \mathrm{~A}$ is about $85 \%$ compared to the use of a current of $110 \mathrm{~A}$ and double by using a melting current of $190 \mathrm{~A}$.

Typical topographies of the cavitated surface highlight a degradation specific to ductile fracture with the formation in isolated material areas of striated craters with a flat bottom.

\section{REFERENCES}

[1] SREEDHAR, B. K., ALBERT, S. K., PANDIT, A. B. Cavitation damage: Theory and measurements - A review. Wear. 2017, vol. 372-373, pp. 177-196.

[2] POLA, A., MONTESANO, L., TOCCI, M., LA VECCHIA, G.M. Influence of ultrasound treatment on cavitation erosion resistance of AISi7 alloy. Materials. 2017, vol. 10, no. 3, p. 256.

[3] LEE, S. J., KIM, K. H., KIM, S. J. Surface analysis of Al-Mg alloy series for ship after cavitation test. Surf. Interface Anal. 2011, vol. 44, pp. 1389-1392.

[4] MITELEA, I. BORDEASU, I., FRANT, F., UTU, I.D. Effect of heat treatment on corrosion and ultrasonic cavitation erosion resistance of AISi10MnMg alloy. Materials Testing. 2020, vol. 62, iss. 9, pp. 92-926.

[5] ASTM G32-16. Standard test method for cavitation erosion using vibratory apparatus. West Conshohocken, PA, USA: ASTM International, 2016.

[6] FRANT, F., MITELEA, I. BORDEASU, I., UTU, I.D., Investigation on ultrasonic cavitation erosion of wrought AlMg alloys. Materials Today-Proceedings. 2021, vol. 45, SI, part 5, pp. $4242-4246$.

[7] TOCCI, M., POLA, A., MONTESANO, L., MARINA LA VECCHIA, G., Evaluation of cavitation erosion resistance of Al-Si casting alloys: Effect of eutectic and intermetallic phases. Fractura ed Integrità Structurale. 2018, vol. 43, pp. $218-230$ 